\title{
Proactive Control of the Growth Behavior of a Thermally Grown Oxide by a Chemically Vapor Deposited $\mathrm{Al}_{2} \mathrm{O}_{3}$ Layer
}

\author{
Y.-F. Su, ${ }^{*}$ L.F. Allard,** D.W. Coffey** and W.Y. Lee* \\ * Department of Chemical, Biochemical, and Materials Engineering, Stevens Institute of \\ Technology, Hoboken, NJ 07070 \\ ** High Temperature Materials Lab., Oak Ridge National Laboratory, Oak Ridge, TN 37831
}

It has been recognized that bond coat oxidation could be a critical factor which limits the lifetime of thermal barrier coatings (TBCs) [1]. Also, it has been reported that TBCs generally fail when the thickness of thermally grown oxide (TGO) which forms on the bond coat surface reaches a critical thickness, in the range of 3 to $10 \mu \mathrm{m}$ [1,2]. Therefore, it is reasonable to project that developing new methods for decreasing the rate of TGO growth is important for prolonging the life of future TBCs. It was postulated that a thin $\alpha-\mathrm{Al}_{2} \mathrm{O}_{3}$ layer, if it could be directly deposited on the surface of a Ni-based superalloy, René N5 (without a bond coat), would guide the superalloy surface to form a TGO that would be more tenacious and slower growing than that which is attainable with state-of-the-art bond coatings.

As has been reported, $\mathrm{Al}^{3+}$ cation would diffuse faster in $\theta-\mathrm{Al}_{2} \mathrm{O}_{3}$ than in $\alpha-\mathrm{Al}_{2} \mathrm{O}_{3}$. Also, the growth rate of $\theta-\mathrm{Al}_{2} \mathrm{O}_{3}$ as a TGO is reported to be about an order of magnitude higher than that of $\alpha-\mathrm{Al}_{2} \mathrm{O}_{3}$ [3-5]. Therefore, it is desirable to form $\alpha-\mathrm{Al}_{2} \mathrm{O}_{3}$ as early as possible to reduce the TGO growth rate, so CVD techniques were used for alumina deposition on the alloy surfaces. TEM samples were prepared by focused ion beam milling using a Hitachi FB-2000 FIB. They were examined in a Hitachi HF-2000 FE-TEM. Figure 1a [6] suggests that the as-deposited $\mathrm{CVD}-\mathrm{Al}_{2} \mathrm{O}_{3}$ layer was $150 \mathrm{~nm}$ thick, and consisted of $\alpha-\mathrm{Al}_{2} \mathrm{O}_{3}$ as the major phase with a minute amount of $\theta-\mathrm{Al}_{2} \mathrm{O}_{3}$. As shown in Figure 1b [7], the TGO-metal interface was highly faceted as the TGO grew towards the metal interface once the mature TGO microstructure (i.e., stagnant) was developed. The faceted feature could be attributed to the plastic deformation of the alloy to accommodate the inward growth of the oxide at the metal-TGO interface. It also implied the TGO mainly grew at the metal-TGO interface as $\mathrm{O}^{2-}$ became the dominant species diffusing along grain boundaries. The formation of the surface ridges has been attributed to $\mathrm{Al}^{3+}$ outward diffusion along short circuit paths (i.e., grain boundaries in the TGO and microcracks formed in the TGO due to the phase transformation of transient oxides to $\alpha-\mathrm{Al}_{2} \mathrm{O}_{3}$ ) during the transient oxidation stage $[8,9]$.

As shown in Figure 2, by comparing the 50h oxidation samples, the average thickness of the TGO formed on the as-polished René N5 surface without the CVD- $\mathrm{Al}_{2} \mathrm{O}_{3}$ layer was $\sim 2.1 \mu \mathrm{m}$ thick as shown in Figure 2a. The classic duplex microstructure was observed for this sample. Strikingly, the average thickness of the TGO layer was $\sim 0.7 \mu \mathrm{m}$ with the $\mathrm{CVD}-\mathrm{Al}_{2} \mathrm{O}_{3}$ layer. The TGO morphology was clearly columnar. These results demonstrated that this thin $\alpha-$ $\mathrm{Al}_{2} \mathrm{O}_{3}$ coating concept could be used as a novel means of favorably altering the TGO growth behavior and consequently increasing the oxidation resistance of Ni-based superalloys. [10]

References

[1] V.K. Tolpgy et al., in Elevated Temperature Coatings: Science and Technology IV, The Minerals, Metals, and Materials Society, Warrendale, PA (2001) 93. 
[2] A.G. Evans et al., Progress in Mater. Sci., 46 (2001) 505.

[3] V.K. Tolpygo et al., Mater. High Temp., 17 (2000) 59.

[4] G.C. Rybicki et al., Oxid. Metals, 31 (1989) 275.

[5] D.R. Clarke, Phys. Stat. Solid. A, 166 (1998), p. 183.

[6] L.M. He et al., Met. Mater. Trans. A, (submitted).

[7] Y.-F. Su, et al., Met. Mater. Trans. A, (submitted).

[8] Y. Zhang et al., Metall. Trans. A, 30A (1999) 2679.

[9] J.K. Doychaket al., Mat. Res, Soc. Symp. Proc., 39 (1985) 475.

[10] This research was sponsored by the U.S. Office of Naval Research (ONR) through Grant N00014-991-0281. We are grateful to Dr. Steven Fishman at ONR for his support and encouragement. Microscopy work was sponsored by the Asst. Secretary for Energy Efficiency and Renewable Energy, Office of Freedom CAR and Vehicle Tech., as part of the High Temperature Materials Laboratory User Program, Oak Ridge National Laboratory, managed by UT-Battelle LLC, for the U.S. DOE.
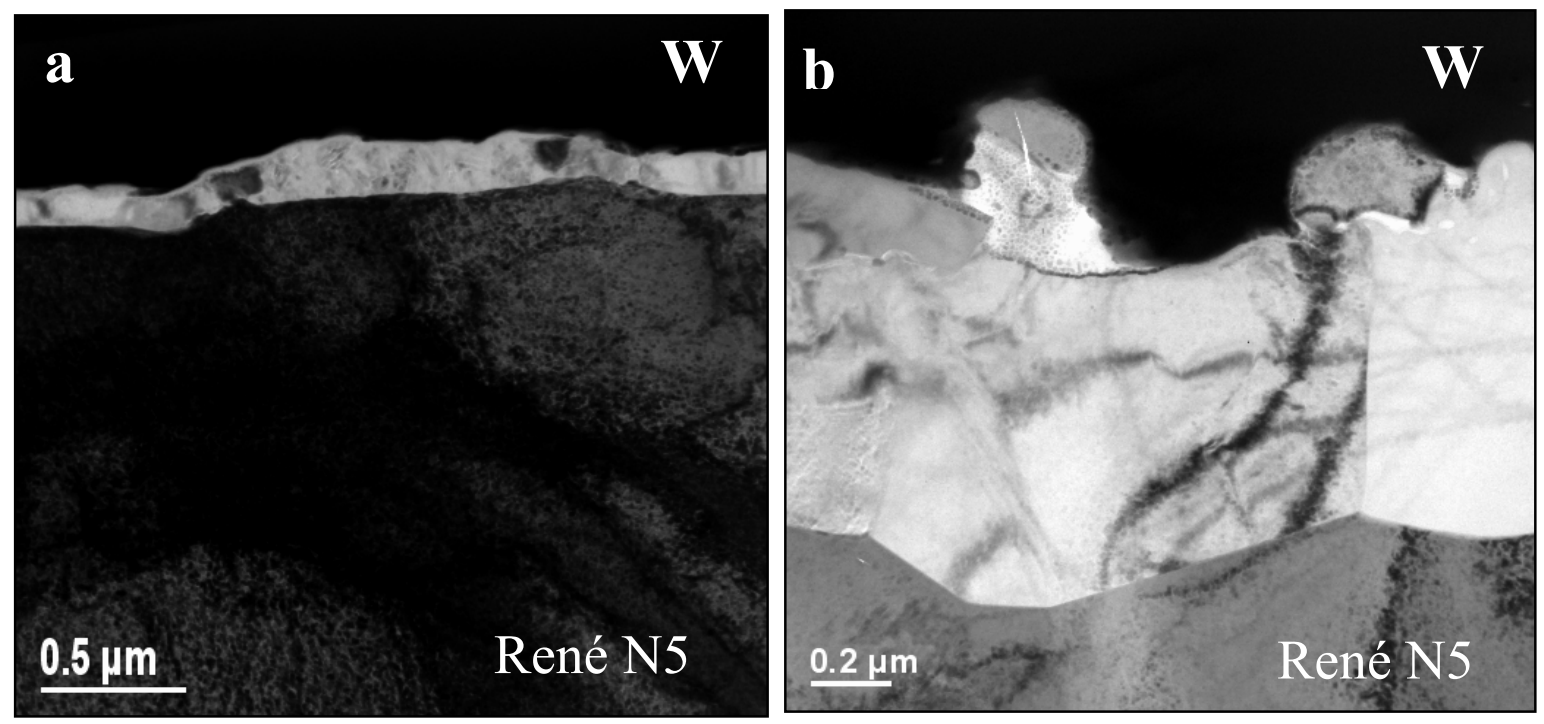

FIG. 1. FIB cross-sectional TEM images (a) as-deposited CVD- $\mathrm{Al}_{2} \mathrm{O}_{3}$, and (b) TGO formed at $1150^{\circ} \mathrm{C}$ for $50 \mathrm{~h}$. Top layer is FIB-deposited $\mathrm{W}$ layer to protect sample.
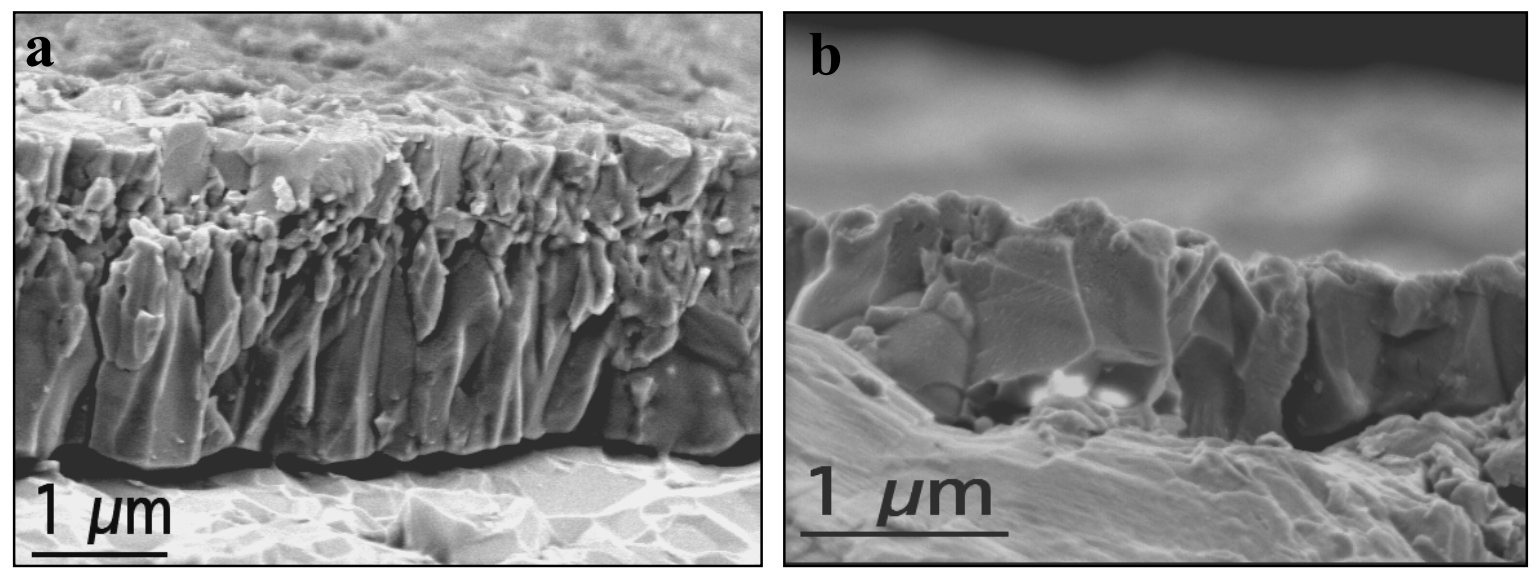

FIG. 2. SEM images of fractured cross-sections of $\mathrm{TGO}$ at $1150^{\circ} \mathrm{C}$ for $50 \mathrm{~h}$ (a) without CVD- $\mathrm{Al}_{2} \mathrm{O}_{3}$, and (b) with $\mathrm{CVD}-\mathrm{Al}_{2} \mathrm{O}_{3}$. 